\title{
Diabetes Mortality: New Light on an Underestimated Public Health Problem
}

\author{
J.H. Fuller ${ }^{1}$, J. Elford*, P. Goldblatt ${ }^{2}$ and A. M. Adelstein ${ }^{3}$ \\ 'Department of Community Medicine, The Middlesex Hospital Medical School, Central Middlesex Hospital, \\ ${ }^{2}$ Office of Population Censuses and Surveys and ${ }^{3}$ Department of Medical Statistics and Epidemiology, \\ The London School of Hygiene and Tropical Medicine, London, UK
}

\begin{abstract}
Summary. Mortality from diabetes is underestimated four- to fivefold by methods of analysis of death certification data which use only underlying cause of death. This problem is partially overcome by coding all conditions mentioned on death certificates. For a sample of deaths in England and Wales over the years 1972-1977, the observed proportion of certificates with specific underlying causes of death for certificates mentioning diabetes was compared with the expected proportion for all certificates. These observed/expected ratios were significantly increased in each sex for circulatory diseases and were significantly reduced for neoplasms. For "ne-
\end{abstract}

phritis' they were also increased, especially below 45 years of age. These results were confirmed by an analysis of underlying cause of death in a cohort of nearly 6,000 members of the British Diabetic Association. Of the 2,134 deaths in this cohort, diabetes was not mentioned on $33 \%$ of the death certificates. For the period 1972-1977, death rates for circulatory diseases associated with diabetes increased by $6 \%$ for males but remained constant for females.

Key words: Diabetes mortality, circulatory diseases, ischaemic heart disease, neoplasms, nephritis.
Diabetes mellitus has become an increasingly important cause of mortality and morbidity in an ageing population [1], nonetheless it has been called 'an underestimated public health problem' [2]. This underestimation occurs partly because, in most countries, mortality statistics are based upon the disease considered to be the "underlying' cause of death and disregard other, often related, diseases diagnosed in the same patient. Another reason is that diabetes, being a chronic disease, is associated with other conditions, such as ischaemic heart disease, which may be more 'visible' to the certifying physician and thus selected as the underlying cause of death in preference to diabetes. The frequency with which diabetes has been cited as the underlying cause of death has varied considerably with time and place, and diabetes is not mentioned at all on the death certificates of a substantial proportion of diabetic subjects [3-5]. Analysis of all conditions mentioned on death certificates may give a clearer picture of the magnitude of diabetes mortality; such data can be used to examine both the distribution of causes of death associated with diabetes and their time trends.

\footnotetext{
* Present address: Department of Clinical Epidemiology and General Practice, The Royal Free Hospital Medical School, Pond Street, Hampstead, London NW3 2QG, UK
}

\section{Methods}

All conditions mentioned on death certificates were coded by the Office of Population Censuses and Surveys (OPCS) for a random sample of national data for England and Wales from 1972 to 1977, excluding 1974. The percentage of death certificates coded in this way varied from $10 \%$ in 1972 to $100 \%$ in 1975 and 1976 , with $25 \%$ samples in 1973 and 1977. In the present analysis, for certificates mentioning diabetes, observed frequencies of particular underlying causes of death were compared with expected frequencies. As shown in the Appendix, the ratio of observed to expected proportions has been calculated excluding certificates with diabetes as the underlying cause of death, and the ratio so obtained is termed a conditional proportional registration ratio $(\mathrm{CPRR}=$ observed/expected proportions $\times 100)$. Where the frequency of a specific underlying cause of death among certificates mentioning diabetes is the same as for the general population, the CPRR equals 100 . The CPRRs for various underlying causes of death have been calculated by year of death, sex, and broad age groups. The statistical significance of deviations of the CPRR from 100 was calculated using a Chi-squared test on one degree of freedom [6]. In the calculation of the CPRR, certificates giving rise to the $o b$ served deaths must have at least two mentioned causes of death, one of which is diabetes. However, in the calculation of the expected deaths, all certificates have been used, some of which only specify one cause of death. It has been calculated that CPRRs based on all certificates do not differ significantly from those derived only from certificates with two or more causes of death mentioned on them. For certificates mentioning diabetes, underlying cause death rates for circulatory diseases, ischaemic heart disease, diabetes and all causes have been estimated for the years 1972-1977 and the rates age-standardised to the year 1975 [7]. 
Further information on mortality among diabetic subjects has been obtained from a prospective study of 5,971 members of the British Diabetic Association resident in England and Wales and recruited between 1965 and 1969. The cohort comprised 3003 males and 2968 females, of whom $35 \%$ and $30 \%$ respectively were below the age of 40 years [8]. Questionnaire responses from a sample of 100 of the cohort indicated that $99 \%$ of the group suffered from diabetes. The study members were 'flagged' at the National Health Service Central Register and the present analysis is based on deaths occurring to this cohort before 1 January 1980 . Causes of death were classified according to the eighth revision of the International Classification of Diseases (ICD).

\section{Results}

\section{Multiple Causes on Death Certification}

Of a total of 1,181,357 death certificates for England and Wales in 1975 and 1976, 3.7\% mentioned diabetes (3.1\% for males and $4.3 \%$ for females). Table 1 shows the distribution of underlying causes of death among certificates mentioning diabetes for 1975 and 1976 combined where $100 \%$ of certificates were multiple-cause coded. The proportion of certificates giving diabetes as the underlying cause of death declined with age, from about $70 \%$ for deaths under 15 years to just over $20 \%$ for deaths 65 years and over. For persons over 45 years, circulatory diseases comprised just over $50 \%$ of underlying causes of death. There were no major sex differences in these proportions for any age group.

The CPRRs for selected underlying causes of death are shown in Table 2 for the years 1975 and 1976 combined. For all circulatory diseases, CPRRs were significantly greater than 100 in both sexes and all age groups, being particularly high for ages $15-44$ years. Women aged 15-64 years had considerably higher CPRRs for ischaemic heart disease compared to men, whereas CPRRs for cerebrovascular disease were higher in men than women for all except the lowest age group. The CPRRs for all neoplasms were significantly lower than 100 for men and for women. A notable exception was pancreatic cancer where the CPRR for men was 117 $(p<0.05)$, but not significantly different from 100 for women. CPRRs were also significantly lower than 100 for bronchitis for all age groups except the youngest, whereas all the CPRRs for pneumonia were significantly increased. For 'nephritis' (ICD 580-584) the CPRRs were consistently increased and were particularly high for the age range 15-44 years, although numbers of expected deaths were small.

The variation in age-adjusted death rates for diabetes as the underlying cause of death over the period 1972-1977 is shown for males and females separately in Figure 1. Rates have remained steady for males but have fallen by $19 \%$ for females over the same period. For certificates mentioning diabetes, not just as the underlying cause of death, Figure 1 also shows underlying cause death rates for circulatory diseases, ischaemic heart disease and all causes. The death rates for certificates mentioning diabetes are just over four times great- 
Table 2. Conditional proportional registration ratios by selected underlying causes of death (1975-1976) (Excluding certificates with diabetes as underlying cause)

\begin{tabular}{|c|c|c|c|c|c|c|c|c|c|c|}
\hline \multirow[t]{3}{*}{ Cause } & \multirow{3}{*}{$\begin{array}{l}\mathrm{ICD}^{\mathrm{a}} \\
\text { code } \\
\text { (8th } \\
\text { revision) }\end{array}$} & \multicolumn{6}{|c|}{ Age (years) } & \multirow{2}{*}{\multicolumn{3}{|c|}{$\begin{array}{l}\text { All ages } \\
\text { (Total number of deaths) }\end{array}$}} \\
\hline & & \multicolumn{2}{|c|}{$15-44$} & \multicolumn{2}{|l|}{$45-64$} & \multicolumn{2}{|l|}{$65+$} & & & \\
\hline & & M & $\mathrm{F}$ & M & $\mathrm{F}$ & $\mathrm{M}$ & $\mathrm{F}$ & M & $F$ & \\
\hline $\begin{array}{l}\text { All circulatory } \\
\text { diseases }\end{array}$ & $390-458$ & $239^{\mathrm{d}}$ & $253^{\mathrm{d}}$ & $138^{\mathrm{d}}$ & $191^{\mathrm{d}}$ & $123^{\mathrm{d}}$ & $119^{\mathrm{d}}$ & $127^{\mathrm{d}}(9,251)$ & $125^{\mathrm{d}}($ & $(13,168)$ \\
\hline $\begin{array}{l}\text { Ischaemic heart } \\
\text { disease }\end{array}$ & $410-414$ & $275^{\mathrm{d}}$ & $473^{\mathrm{d}}$ & $130^{\mathrm{d}}$ & $231^{\mathrm{d}}$ & $123^{\mathrm{d}}$ & $130^{\mathrm{d}}$ & $125^{\mathrm{d}}(5,491)$ & $140^{\mathrm{d}}$ & $(6,372)$ \\
\hline $\begin{array}{l}\text { Cerebrovascular } \\
\text { disease }\end{array}$ & $430-438$ & 162 & $240^{\mathrm{d}}$ & $237^{\mathrm{d}}$ & $173^{\mathrm{d}}$ & $145^{\mathrm{d}}$ & $124^{\mathrm{d}}$ & $152^{\mathrm{d}}(2,280)$ & $127^{\mathrm{d}}$ & $(4,110)$ \\
\hline Other heart disease & $420-429$ & $156^{\mathrm{b}}$ & 109 & $158^{\mathrm{d}}$ & $170^{\mathrm{d}}$ & $113^{\mathrm{d}}$ & 99 & $118^{d} \quad(635)$ & 102 & $(1,184)$ \\
\hline All neoplasms & $140-239$ & $47^{d}$ & $30^{\mathrm{d}}$ & $45^{\mathrm{d}}$ & $28^{d}$ & $53^{d}$ & $46^{\mathrm{d}}$ & $51^{\mathrm{d}}(1,641)$ & $41^{\mathrm{d}}$ & $(1,494)$ \\
\hline $\begin{array}{l}\text { All respiratory } \\
\text { diseases }\end{array}$ & $460-519$ & $206^{\mathrm{d}}$ & $226^{\mathrm{d}}$ & 91 & 110 & 98 & 104 & $97(2,291)$ & 104 & $(2,939)$ \\
\hline Pneumonia & $480-486$ & $249^{d}$ & $322^{\mathrm{b}}$ & $160^{\mathrm{d}}$ & $164^{d}$ & $133^{\mathrm{d}}$ & $113^{\mathrm{d}}$ & $136^{\mathrm{d}}(1,544)$ & $115^{\mathrm{d}}$ & $(2,338)$ \\
\hline Bronchitis & $490-492$ & $166^{\mathrm{b}}$ & $136^{\mathrm{b}}$ & $45^{\mathrm{d}}$ & $49^{d}$ & $53^{\mathrm{d}}$ & $64^{\mathrm{d}}$ & $52^{\mathrm{d}} \quad(495)$ & $62^{\mathrm{d}}$ & (261) \\
\hline Nephritis & $580-584$ & $686^{\mathrm{b}}$ & $277^{\mathrm{b}}$ & $161^{c}$ & $203^{\mathrm{d}}$ & $177^{\mathrm{d}}$ & $148^{\mathrm{d}}$ & $185^{\mathrm{d}} \quad(135)$ & $159^{d}$ & $(150)$ \\
\hline $\begin{array}{l}\text { All causes } \\
\text { (total number of deat }\end{array}$ & & $\begin{array}{l}100 \\
(178)\end{array}$ & $\begin{array}{l}100 \\
(112)\end{array}$ & $\begin{array}{l}100 \\
(2,958)\end{array}$ & $\begin{array}{l}100 \\
(2,291)\end{array}$ & $\begin{array}{l}100 \\
(10,982)\end{array}$ & $\begin{array}{l}100 \\
(16,627)\end{array}$ & $\begin{array}{l}100 \\
(14,125)\end{array}$ & $\begin{array}{l}100 \\
(19,04\end{array}$ & \\
\hline
\end{tabular}

a International Classification of Diseases; ${ }^{b}$ expected number of certificates $<5$; significance of deviation of CPRR from 100:-

${ }^{\mathrm{c}} p<0.05,{ }^{\mathrm{d}} p<0.01$; total number of deaths in parentheses

er over the period 1972-1977 than the rates for diabetes coded as the underlying cause of death and they have risen by $12 \%$ for males and fallen by $6 \%$ for females. For persons with diabetes mentioned on the death certificate, the changes in underlying cause death rates for all circulatory diseases were $+6 \%$ (males) and $0 \%$ (females) and, for ischaemic heart disease, $+20 \%$ (males) and $-7 \%$ (females).

\section{Study of British Diabetic Association Members}

The cohort of 5,971 members of the British Diabetic Association has been followed up for mortality for between 11 and 14 years. For deaths over that period, 2,134 death certificates were traced and coded for cause of death. Of these, 1,436 (67\%) had diabetes mentioned on them, either as the underlying cause or a contributory cause of death. The distribution of major underlying causes of death is shown in Table 3 for (A) all coded death certificates and (B) those certificates mentioning diabetes. When certificates giving diabetes as the underlying cause were excluded, diabetes was mentioned as a contributory cause on $60 \%$ of the remaining 1,742 certificates. This proportion varied with the underlying cause of death, being highest for respiratory diseases $(69 \%)$, and lowest for accidents (18\%). The proportion for neoplasms (51\%) was lower than that for circulatory diseases $(62 \%)$.

Mortality of the British Diabetic Association cohort has been compared with that of the general population of England and Wales for 1972 by calculating standardised mortality ratios (observed/expected deaths $\times 100$ ) for specific underlying causes of death by sex and age (Table 4). The standardised mortality ratios for all causes, all circulatory diseases and ischaemic heart disease were significantly greater than 100 , the values for women being higher than those for men for all age groups. For women in the British Diabetic Association cohort aged 15-44 years, the particularly high standardised mortality ratio of 1,145 for ischaemic heart disease indicates that they are more than 11 times more likely to die of ischaemic heart disease than women of the general population in the same age range. The standardised mortality ratios for neoplasms as a whole were not significantly different from 100 for men or for women. For all respiratory diseases, the standardised mortality ratios were significantly lower than 100 for men and higher than 100 for women.

\section{Discussion}

The introduction of insulin therapy in 1922-1923 resulted in a prompt fall in diabetes death rates in England and Wales for the age range 15-44 years [9]. However, Reid and Evans [10] pointed out that the impact of insulin therapy on the overall mortality of diabetic patients was slight, since there was little benefit for the older age groups where most deaths occur. One consequence of the prolongation of the diabetic life, mainly as a result of insulin therapy, has been the growing contribution of 

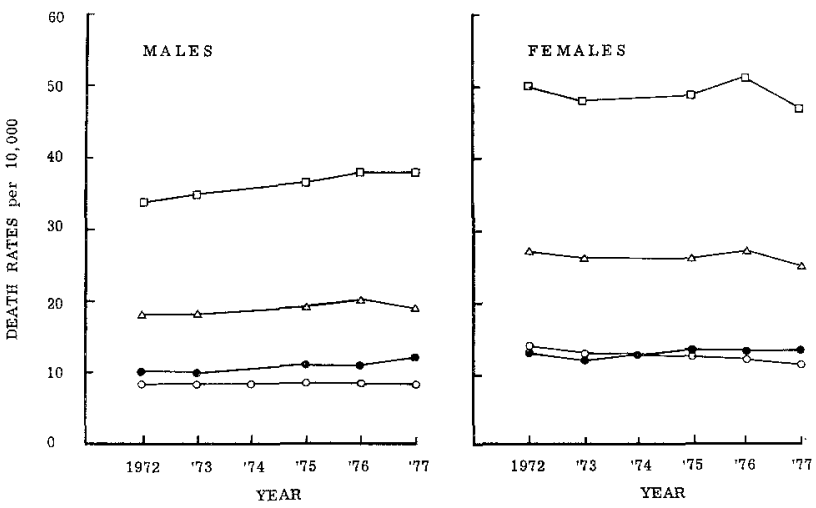

Fig 1. Death rates per 10,000 population for England and Wales 1972-1977, age-standardised to the year 1975, for death certificates mentioning diabetes and the following underlying causes of death: diabetes $(O)$, ischaemic heart disease $(\bullet)$, all circulatory diseases $(\Delta)$ and all causes $(\square)$. International Classification of Diseases categories as in tables

Table 3. British Diabetic Association cohort 1966-1979: proportion of death certificates mentioning diabetes

\begin{tabular}{lccc}
\hline Underlying cause & $\begin{array}{l}\text { All coded } \\
\text { death } \\
\text { certificates } \\
\text { (A) }\end{array}$ & $\begin{array}{l}\text { Death } \\
\text { certificates } \\
\text { mentioning } \\
\text { diabetes (B) }\end{array}$ & $\begin{array}{l}\text { (B) as a } \\
\% \text { of (A) }\end{array}$ \\
\hline $\begin{array}{l}\text { All circulatory } \\
\text { diseases }\end{array}$ & 1,128 & 700 & 62 \\
All neoplasms & 247 & 126 & 51 \\
$\begin{array}{l}\text { All respiratory } \\
\text { diseases }\end{array}$ & 208 & 144 & 69 \\
$\begin{array}{l}\text { Accidents } \\
\text { Other }\end{array}$ & 44 & 8 & 18 \\
\hline $\begin{array}{l}\text { Total (excluding } \\
\text { diabetes as an }\end{array}$ & 115 & 66 & 57 \\
\hline underlying cause) & 1,742 & 1,044 & 60 \\
\hline Diabetes & 392 & 392 & 100 \\
\hline Total & 2,134 & 1,436 & 67 \\
\hline
\end{tabular}

macrovascular complications to mortality $[3,11]$. This changing pattern of diabetic fatality, and the certifying physician's appreciation of it, have been associated with substantial changes in mortality statistics over the last half century. In England and Wales during the period 1921-1930, diabetes was classified as the underlying cause of death in $91 \%$ of certificates mentioning diabetes [9] but in only $60 \%$ in 1939 [12], 33\% in 1955 [13], and is now down to $22 \%$ for men and $24 \%$ for women. A similar fall in the proportion of deaths assigned to diabetes as underlying cause was noted in a 26-year follow-up study of patients attending the Joslin Clinic [14]. Since routine mortality statistics only consider the underlying cause of death, this trend has resulted in an increasing underestimation of the contribution of diabetes to overall mortality, particularly for the middleand older-age ranges.
A clearer picture of the pattern of mortality in diabetic subjects can be obtained by coding all conditions mentioned on death certificates. Data from England and Wales confirm the findings in other developed countries $[2,11,15]$ that circulatory diseases are the underlying cause of death in just over $50 \%$ of certificates mentioning diabetes. The high toll of circulatory diseases recently reported for diabetic patients under the age of 50 years [16] is reflected in the high CPRRs for total circulatory diseases and ischaemic heart disease for the age range 15-44 years. The increased cardiovascular risk of younger diabetic women, shown in several studies [17-19], is confirmed here by the high CPRRs for the national data and high standardised mortality ratios for the British Diabetic Association cohort, and is so far unexplained in terms of established cardiovascular risk factors [3].

The relationship between cerebrovascular disease and diabetes is unclear, with some studies showing an increased incidence of stroke amongst diabetic subjects and others not [3]. The current analysis shows significantly raised CPRRs for cerebrovascular disease for all except the lowest age group for men (Table 1). Standardised mortality ratios for cerebrovascular disease were also increased in the British Diabetic Association cohort (Table 3).

The excess risk of the diabetic for death from renal disease is well documented [3,11] and confirmed by the increased CPRRs for 'nephritis' for all age-ranges, but particularly for the 15-44 year age group. The CPRRs for all respiratory diseases were not significantly different from 100 but the corresponding standardised mortality ratios were increased for the women in the British Diabetic Association cohort. An excess of deaths due to respiratory infection in diabetics has been reported elsewhere [19] and is confirmed by the increased CPRRs for pneumonia in all age groups, but the contrasting low CPRRs for bronchitis have not previously been noted.

A striking feature of the multiple-cause analysis was the low CPRRs for most cancers. Many previous studies showing an excess cancer mortality associated with diabetes have been criticised by Kessler [20] for their lax definitions of diabetes and the inadequacy of control groups. Kessler's own study of a cohort of diabetic patients attending the Joslin Clinic showed a reduced standardised mortality ratio for all cancers combined in men (particularly cancer of the lung), but not in women, and there was a significantly increased risk of pancreatic cancer for both men and women [21]. A lowered cancer risk, particularly for women, was also found in Edinburgh [19], but not in Birmingham, UK [22]. With an excess of early deaths in diabetic patients from circulatory diseases, part of the lowered mortality from cancer and bronchitis may be due to the phenomenon of 'competing risk', since with a proportional analysis, an excess of one particular underlying cause of death must lead to a deficit in others. However, this is unlikely to be the whole explanation of the generally low CPRRs for 
Table 4. British Diabetic Association cohort 1966-1979: standardised mortality ratios by selected underlying causes of death

\begin{tabular}{|c|c|c|c|c|c|c|c|c|c|}
\hline \multirow[t]{2}{*}{ Cause } & \multirow{2}{*}{$\begin{array}{l}\mathrm{ICD}^{\mathrm{a}} \\
\text { code } \\
\text { (8th } \\
\text { revision) }\end{array}$} & \multicolumn{6}{|c|}{ Age (years) } & \multicolumn{2}{|c|}{$\begin{array}{l}\text { All ages } \\
\text { (Number of deaths) }\end{array}$} \\
\hline & & M & $\mathrm{F}$ & M & $\mathrm{F}$ & M & $F$ & M & $\mathrm{F}$ \\
\hline $\begin{array}{l}\text { All circulatory } \\
\text { diseases }\end{array}$ & $390-458$ & $457^{\mathrm{b}}$ & $631^{b}$ & $210^{\mathrm{d}}$ & $319^{d}$ & $149^{d}$ & $187^{\mathrm{d}}$ & $164^{\mathrm{d}}(542)$ & $199^{d}(586)$ \\
\hline $\begin{array}{l}\text { Ischaemic heart } \\
\text { disease }\end{array}$ & $410-414$ & $498^{b}$ & $1,154^{b}$ & $384^{d}$ & $432^{d}$ & $174^{\mathrm{d}}$ & $257^{\mathrm{d}}$ & $187^{\mathrm{d}}(367)$ & $274^{\mathrm{d}}(346)$ \\
\hline $\begin{array}{l}\text { Cerebrovascular } \\
\text { disease }\end{array}$ & $430-438$ & $392^{\mathrm{b}}$ & $541^{\mathrm{b}}$ & 102 & 175 & $145^{\mathrm{d}}$ & $138^{\mathrm{d}}$ & $142^{\mathrm{d}}(105)$ & $142^{d}(131)$ \\
\hline All neoplasms & $140-239$ & $115^{\mathrm{b}}$ & $224^{b}$ & 86 & 97 & 89 & 110 & $89(132)$ & 109 (115) \\
\hline $\begin{array}{l}\text { All respiratory } \\
\text { diseases }\end{array}$ & $460-519$ & $125^{b}$ & $667^{b}$ & 92 & $321^{\mathrm{d}}$ & $78^{\mathrm{c}}$ & $158^{\mathrm{d}}$ & $81^{\mathrm{c}} \quad(89)$ & $173^{\mathrm{d}}(119)$ \\
\hline
\end{tabular}

${ }^{a}$ International Classification of Diseases ${ }^{b}$ Expected number of deaths $<5$. Significance of deviation of standardised mortality ratio from 100:- ${ }^{\circ} p<0.05$, d $p<0.001$. Total number of deaths in parentheses

cancers and bronchitis since they remain low even in the oldest age range where the CPRRs for circulatory diseases have come significantly closer to 100 . The British Diabetic Association cohort analysis also indicates that diabetes may not be mentioned so frequently on death certificates with cancer as the underlying cause (51\% versus $60 \%$ for all causes except diabetes). However, this degree of under-reporting does not seem likely to be the whole explanation of the generalised low CPRRs for cancers which deserves further study.

The interpretation of epidemiological research based on death certification data has been questioned by some [23], mainly in terms of the accuracy of the information. A recent autopsy study showed that the underlying cause of death, assigned by the pathologist, was mentioned on the death certificates in $72 \%$ of cases [24]. Multiple-cause analysis, where all conditions mentioned on the certificate, and not just the underlying cause, are analysed, has obvious advantages for a condition such as diabetes. As a measure of the impact of a disease on the community, mortality information based on death certification has several advantages over clinical cohort studies. These include its relative ease of processing, the comprehensive nature of its data-base and its usefulness for indicating long-term trends [25].

The trends of diabetic death rates, even though analysed over a relatively short period, certainly give no indication that recent developments in the management of diabetes, particularly concern over the quality of diabetic control [26], are having a rapid impact on diabetic mortality. What is certain is that diabetes, as a contributor to overall mortality, is being underestimated at least four- or fivefold when reliance is placed on underlying cause of death alone and this emphasizes the need for continued monitoring of all conditions mentioned at death in diabetic subjects.
Acknowledgements. JE was supported by a research grant from the British Diabetic Association. We thank Miss S.Dolley and Mr.S. Edmeades for their skilled assistance.

\section{References}

1. Keen H, Fuller JH (1980) The epidemiology of diabetes. In: Exton-Smith AN, Caird FI (eds) Metabolic and nutritional disorders in the elderly. John Wright, Bristol, pp 146-160

2. Tokuhata GK, Miller W, Digon E, Hartman T (1975) Diabetes mellitus: an underestimated public health problem. J Chron Dis $28: 23-35$

3. West KM (1978) Epidemiology of diabetes and its vascular lesions. Elsevier, New York

4. Tokuhata GK (1976) Report of the workgroup on mortality of the committee on scope and impact to the National Commission on Diabetes. National Institutes of Health, Bethesda, NIH Publication No. 76 - 1021, 3 (Part 1), pp 179-225

5. O'Sullivan JB, Mahan CM (1982) Mortality related to diabetes and blood glucose levels in a community study. Am J Epidemiol 116: 678-684

6. Armitage P (1971) Statistical methods in medical research. Blackwell Scientific Publications, Oxford

7. Office of Population Censuses and Surveys (1983) Supplement DH2. Her Majesty's Stationery Office London (in press)

8. Armstrong B, Lea AJ, Adelstein AM, Donovan JW, White GC, Ruttle S (1976) Cancer mortality and saccharin consumption in diabetics. Br J Prev Soc Med 30: 151-157

9. Stocks P (1944) Diabetes mortality in 1861-1942 and some of the factors affecting it. J Hyg 43: 242-247

10. Reid DD, Evans JG (1970) New drugs and changing mortality from non-infectious disease in England and Wales. Br Med Bull 26: 191-196

11. Marks HH, Krall LP (1971) Onset, course, prognosis and mortality in diabetes mellitus. In: Marble A, White P, Bradley RF, Krall LP (eds) Joslin's Diabetes Mellitus, 11th edn. Lea \& Febiger, Philadelphia, pp 209-254

12. Registrar General (1947) Registrar General's statistical review of England and Wales for the years 1938 and 1939. Her Majesty's Stationery Office, London

13. Registrar General (1957) Registrar General's statistical review of England and Wales for the year 1955. Part 3: Commentary. Her Majesty's Stationery Office, London 
14. Kessler II (1971) Mortality experience of diabetic patients. A twenty-six year follow-up study. Am J Med 51: 715-724

15. Sasaki A, Kamado K, Horuchi N (1978) A changing pattern of causes of death in Japanese diabetics. Observations over fifteen years. J Chron Dis 31 : $433-444$

16. Tunbridge WMG (1981) Factors contributing to deaths of diabetics under fifty years of age. Lancet 2: 569-572

17. Entmacher PS, Root HF, Marks HH (1964) Longevity of diabetic patients in recent years. Diabetes 13: 373-377

18. Krolewski AS, Czyzyk A, Janeczko D, Lopcynski J (1977) Mortality from cardiovascular disease among diabetics. Diabetologia 13: $345-350$

19. Shenfield GM, Elton RA, Bhalla IP, Duncan LJP (1979) Diabetic mortality in Edinburgh. Diabete Metab 5: 149-158

20. Kessler II (1971) Cancer and diabetes mellitus. A review of the literature. J Chron Dis 23: 579-600

21. Kessler II (1970) Cancer mortality among diabetics. J Natl Cancer Inst 44: 673-686

22. Hayward RE, Lucena BC (1965) An investigation into the mortality of diabetics. J Inst Act $91: 286-336$

23. Medical Services Study Group of the Royal College of Physicians of London (1978) Death certification and epidemiological research. Br Med J 2: 1063-1065

24. Engel LW, Strauchen JA, Chiazze L, Heid M (1980) Accuracy of death certification in an autopsied population with specific attention to malignant neoplasms and vascular diseases. Am J Epidemiol 111: $99-112$

25. Adelstein AM (1978) Death certification and epidemiological research. Br Med J 2: 1229-1230

26. Tchobroutsky G (1978) Relation of diabetic control to development of micro-vascular complications. Diabetologia 15: 143-152

Received: 12 July 1982

and in revised form: 3 February 1983
Appendix Calculation of conditional proportional
registration ratios (CPRR)

In this article the conditional proportional registration ratio (CPRR) for a specific cause of death is calculated as:

$(\mathrm{O} / \mathrm{E}) \times 100$

where

$\mathrm{O}=$ observed number of certificates which are assigned to the condition as underlying cause of death and which contain a mention of diabetes; $E=$ number expected among all certificates which contain a mention of diabetes (but not as underlying cause), if it is assumed that such certificates have the same distribution by underlying cause as is found among all other certificates registered in the same year (for each sex and broad age group). Thus, formally, for each sex and year of registration:

$\mathrm{E}=$ sum over broad age groups of $\mathrm{D} \times(\mathrm{C} / \mathrm{T})$

where

$\mathrm{D}=$ Number of certificates which mention diabetes but are not assigned to diabetes as underlying cause; $\mathrm{C}=$ Total number of certificates assigned to the condition of interest as underlying cause; $\mathrm{T}=$ Total number of certificates registered excluding those assigned to diabetes as underlying cause of death.

Dr. J.H. Fuller

Department of Community Medicine

Central Middlesex Hospital

London NW10 7NS, UK 